\title{
THE RED CROSS AND PHILATELY
}

The Centenary Commission of the Red Cross in Switzerland which has already published several works in connection with the events which took place in Geneva, Lausanne and Macolin, has now produced a booklet with a large number of illustrations. ${ }^{1}$

Mention should be made of the excellent study by Mr. Max-Marc Thomas of the relations of the Red Cross and philately which appeared in the International Review (October 1964). Mr. C. Rouard Watine, head of information and publicity of the French Red Cross, has also made a valuable contribution to the subject in this booklet. He describes the connections which exist between the Red Cross, the Post and the postage-stamp, extracts of which we give below.

... The connection between the Red Cross and the post goes back to the beginning of the Red Cross when postage exemption was granted to the National Red Cross Societies. In France, for example, on July 12, 1870, the Post Department Director-General granted exemption on mail despatched by the National Aid Society for the Nursing of the Sick and Wounded in the Field. The Swiss Postal Administration, in its Service Orders No. 95 and No. 105 of July 28 and August 5, 1970, granted postage exemption " to International Societies established in Switzerland pursuant to the Geneva Convention of August 25, 1864 ". The French Service Order of July 12,1870, made it a condition that the sender's name should be shown by means of a rubber stamp or by hand. In order to facilitate postage, most of the National Aid Societies used adhesive labels showing the red cross, in preference to a rubber stamp imprint. Consequently, these labels being issued by the Red Cross organizations themselves, and not by the postal authorities, they cannot be considered as postage-stamps.

On August 6, 1870, the German Post Department DirectorGeneral, Berlin, in Service Order No. 24, conferred exemption from postal charges on mail for prisoners of war. This correspondence had to be marked "Porto frei laut Verfügung vom 7. August 1870".

1 The Red Cross and Philately, Geneva 1965. This booklet, published in French and English, is available for 2 Sw.frs. from the League of Red Cross Societies, Geneva. 


\section{IN THE RED CROSS WORLD}

It was not until 1889 , in Portugal, that the first Red Cross stamp appeared, and only during the 1914-18 war did the issue of Red Cross stamps beccme widespread. In those four years, there were no less than 66 issues in 47 countries, comprising 230 stamps. Nearly all were for the purpose of raising funds for the National Red Cross Societies to enable them to carry out their many relief tasks. The success achieved by these issues greatly influenced the subsequent development of this type of postage-stamp, called semi-postage-stamp. The aim of such issues is twofold, i.e. as postage and as an aid to charity.

The yield from the surcharge on Red Cross stamps from 1914-18 can be estimated at several tens of millions of francs, not counting the proceeds of the sales of vignettes unconnected with postage and which also flourished during the same period.

The same fund-raising procedure was resumed in many European and South American countries, shortly before the Second World War. In Finland, for example, since 1930, there have been special issues each year for the benefit of the Red Cross. It may be noted with interest that the construction of the Belgian Red Cross headquarters in Brussels was financed by a series of issues in 1939. In France, the surcharge on postage-stamps has been contributing to Red Cross emergency activities since 1950.

In a number of countries, including Greece, Turkey, Yugoslavia and Colombia, there is another type of Red Cross stamp which is compulsory for internal mail for a specific period, in addition to the normal postage-stamp. The proceeds are paid in full to the Red Cross Society.

Most Red Cross stamps are special issues for charitable purposes. They include issues commemorating important events in the history of the Red Cross, many bearing effigies of the founders of the movement. There are also issues without any surcharge, some for air mail and some for express mail.

The country which has issued most Red Cross stamps is Spain, with 148 different values; they are valid both internally and in Spanish possessions. The first country to issue Red Cross stamps with a surcharge was France in 1914. Since then, France has made 154 such issues in the Metropole and in its overseas territories.

It is natural that the nurse provides the motif for most designers 
and engravers. She is displayed on stamps issued in the USA, South Africa, Costa Rica, Haiti, France, Albania, Bulgaria, Finland, Poland, Rumania, Ethiopia, Bohemia, Estonia, Hungary, Iceland, Japan, Norway, Nicaragua, Turkey and Germany.

Some stamps portray Red Cross activities, such as blood transfusion in the Netherlands, Belgium, Hungary, and Finland; disaster relief in Bulgaria and Liechtenstein; first-aid in the Netherlands; hospital ships in Denmark and Turkey; hospital trains in Bulgaria, etc.

Important events in Red Cross history are also illustrated. A Finnish stamp for example depicts the battle of Solferino, where the suffering of the wounded roused Dunant's determination. His portrait is shown on Swiss, Belgian, French, German and Portuguese stamps. Florence Nightingale, who gave inspiration to Henry Dunant, is portrayed on Belgian, Portuguese and Costa Rican stamps. Clara Barton, the founder of the American Red Cross, figures on a United States stamp and Elsa Brandström " the Swedish white angel " on a German stamp.

In 1939, 1944, 1952 and 1959 many countries commemorated their accession to the Geneva Conventions or recalled the centenary of the birth of the Red Cross idea. In 1939, the Third Pan-American Conference of the Red Cross was commemorated by Brazil ; the XVth International Conference of the Red Cross by Japan in 1934 with an issue of four stamps and the XVIIIth International Conference by Canada in 1952; the XIXth International Conference of the Red Cross at New Delhi by India with a special issue. Similarly, in October 1965, the XXth Conference was commemorated by an Austrian stamp. Many countries have celebrated their National Society's anniversary, such as the United States in 1931 and France in 1939.

The Centenary of the birth of the Red Cross was the occasion for an even greater number of new stamps: 136 countries and territories made such issues to mark this anniversary. Many of these countries, like the United Kingdom and most of the Crown Colonies and Commonwealth Territories, dedicated a stamp to the Red Cross for the first time. In 1964, four stamps in Finland were issued to mark the Centenary of the First Geneva Convention; each one, of a different value, was symbolic of the four Conventions of 1949 to which most of the countries of the world have acceded. 


\section{IN THE RED CROSS WORID}

What is the total value of all these stamps ? Number 54 of the Yvert catalogue and the Moroccan Tellier quote them at over Fr. 7,000 and, indeed, some Borneo and Thailand series are very rare, but on the whole they are reasonably priced. Nevertheless, to assemble these 2094 stamps requires all the wiles of the collectors' art. However, it is not on the material value of such a collection that we shall dwell, but on the constantly renewed interest to be derived from collecting so many testimonies to a universal activity. New States become independent, new Red Cross or Red Crescent stamps make their appearance; peace returns to some distant part of the world and through stamps a tribute is paid to the work of the Red Cross during the conflict. In addition, the postmark itself may attest to the relief work carried out under the sign of the red cross.

Andre Siegfried said "the stamp is the expressive symbol of communication among men ". It is a good thing for the postage stamp to be closely associated with the life of the Red Cross; the same Red Cross that is ever present to alleviate suffering throughout the world. In a variety of ways, across frontiers, oceans, and skies the world over, postal authorities have united and continue to unite their efforts and activities to those of the Red Cross in the service of mankind. 